\title{
"UM BERÇO PARA A CIVILIZAÇÃO DO SERTÃO": A CIDADE DE POMBAL E SUAS REPRESENTAÇÕES IDENTITÁRIAS NO INTERIOR PARAIBANO
}

\author{
Rodrigo Ceballos, UFCG \\ Larissa Daniele Monteiro Lacerda, UFCG
}

\begin{abstract}
RESUMO
A cidade de Pombal, situada no alto sertão paraibano, se constituiu ao longo do século XVIII como o primeiro núcleo habitacional do sertão, organizado por um aparelho administrativo e jurídico que lhe proporcionou centralidade política no período colonial. A perda dessa capilaridade histórica, ao longo do século XIX, com o surgimento de outros núcleos urbanos, propiciou no século XX a formação de saberes disciplinadores emoldurados por professores, clérigos, intelectuais de uma elite política paraibana, membros do IHGP e comunicadores sociais legitimadores da relevância social, cultural e política de uma cidade "berço da civilização sertaneja". Analisamos, neste breve estudo, como determinados discursos locais produziram verdades elaboradoras de uma identidade para a região, patrimonializadas nos espaços educacionais, religiosos e políticos. Argumentaremos sobre algumas representações que lutam pela centralidade histórica para Pombal e como seus usos cotidianos por meio de seus atores sociais são incorporados por meio de sua arquitetura, personagens históricos ou festas religiosas.
\end{abstract}

PALAVRAS-CHAVE: História da Paraíba; educação; identidade.

\section{"A CRADLE OF A 'SERTANEJA' CIVILIZATION": THE CITY OF POMBAL AND ITS IDENTITIES REPRESENTATIONS IN THE PARAÍBA HINTERLAND}

\begin{abstract}
Pombal city, located at the alto sertão da Paraíba, was constituted during the $18^{\text {th }}$ Century as the first housing center of the sertão, organized by an administrative and juridical apparatus that gave it political centrality in the colonial period. Along the $19^{\text {th }}$ Century Pombal have lost its historical importance because of the growth of other urban centers. At the $20^{\text {th }}$ Century professors, teachers, clerics, IHGP members, political elites of the city contributed to create a "cradle of a 'sertaneja' civilization". This brief study aims to analyze how certain local discourses elaborated a genuine identity to a region, endorsed by the educational, religious and political spaces. We argue about some representations that enhance Pombal's historical centrality by their daily uses incorporated from its architecture, historical figures or religious festivals.
\end{abstract}

KEYWORDS: Paraíba History; representation; identity. 


\title{
"UNA CUNA PARA LA CIVILIZACIÓN 'SERTANEJA": LA CIUDAD DE POMBAL Y SUS REPRESENTACIONES IDENTITARIAS EN EL INTERIOR PARAIBANO
}

\begin{abstract}
RESÚMEN
La ciudad e Pombal, situada en el alto sertão paraibano, se constituyó a lo largo del siglo XVIII como el primer núcleo de población del sertão, organizado por un aparato administrativo y jurídico que le proporcionó una centralidad política en el período colonial. La pérdida de esta centralidad histórica, a lo largo del siglo XIX, con el aparecimiento de otros núcleos urbanos, proporcionó en el siglo XX la formación de saberes disciplinarios enmarcados por profesores, clérigos, intelectuales de una élite política paraibana, miembros del IHGP e comunicadores sociales legitimadores de la relevancia social, cultural e política de una ciudad "cuna de la civilización sertaneja". Analizaremos, en este breve estudio, como algunos discursos locales produjeron verdades elaboradoras de una identidad para la región, patrimonializadas en los espacios educacionales, religiosos y políticos. Argumentaremos sobre algunas representaciones que lucharon por una centralidad histórica para Pombal y como sus usos cotidianos por medio de sus actores sociales fueron incorporados por medio de su arquitectura, personajes históricos o fiestas religiosas.
\end{abstract}

PALABRAS-CLAVE: Historia de la Paraíba; educación; identidad.

\section{INTRODUÇÃO}

Quando fui à igreja da nova Matriz de Nossa Senhora do Bom Sucesso em maio deste ano, surpreendi-me com o sermão do padre celebrando em missa a comemoração da padroeira da cidade de Pombal, Nossa Senhora do Bom Sucesso. Suas palavras ecoaram em mim e reafirmaram signos que aprendi desde criança. O clérigo afirmava com veemência que a cidade que vivíamos tem um valor histórico e cultural inigualável a qualquer outra cidade do sertão paraibano; uma importância social que a distinguia das demais, pois ela teria sido a primeira povoação do alto sertão e o berço da sua civilização e expansão da religião católica. Se por um lado Cajazeiras "ensinou a Paraíba a ler", Pombal "ensinou o homem do sertão a rezar, a buscar sua salvação junto a Deus Pai Todo Poderoso"1. Tempos atrás, a rádio local transmitiu entrevista com um

\footnotetext{
${ }^{1}$ Relato da coautora desse texto, Larissa Daniele M. Lacerda, presente na missa de comemoração a padroeira da cidade, Nossa Senhora do Bom Sucesso, em 21 de maio de 2017 na cidade de Pombal (PB).
} 
consagrado pesquisador da cidade, relatando os atos heroicos dos membros da Casa da Torre ou dos Oliveira Ledo que marcaram a fundação da cidade. ${ }^{2}$

Dei-me conta que a cidade de Pombal está envolta em uma aura divina, valorizada por falas construtoras de uma tradição histórico-religiosa. Em sua obra "Um olhar sobre Pombal antiga (1906 a 1970)", o pesquisador Verneck Sousa afirma que "Pombal foi o berço, a porta de entrada para civilização sertaneja" (SOUSA, 2002, p. 9). Maria do Socorro Martins, licenciada em História, reforça esta imagem: "Tenho orgulho de ser filha de uma terra de história e tradição" (MARTINS, 2016, p. 9). E nas mídias sociais também cristaliza-se seu símbolo maior: "Pombal é uma cidade bela, situada no alto sertão da Paraíba, de grandes filhos ilustres, de um povo que tem uma cultura privilegiada e que sentem amor por sua terra natal" (ABRANTES, 2010). Mesmo com matizes distintas, o discurso é o mesmo, reproduzido de geração a geração, atribuindo à cidade um significado histórico, cultural e político distinguindo-a das demais cidade paraibanas. As falas respaldam-se principalmente nos estudos realizados por consagrados estudiosos como Wilson Seixas, Verneck Abrantes e Jerdivan Nóbrega ${ }^{3}$.

Bombardeados quase cotidianamente pelas "falas eméritas da cidade", difundidas pelas mídias e por instituições (religiosas ou civis), passamos a naturalizálas, a reproduzi-las e integrá-la em nossa identidade local (e até regional). Para muitos sertanejos interessados em suas genealogias, seus ascendentes ainda são encontrados nos velhos Livros de Notas do século XVIII, resguardados no antigo Cartório no centro da cidade. A poucos metros, em frente a praça, está a primeira igreja do velho povoado, considerada uma das mais antigas de toda a Paraíba. A estrutura da igrejinha do Rosário, antiga Matriz de Nossa Senhora do Bom Sucesso, manteve-se em pé, para orgulho do padre em sua fala dominical. Seu cruzeiro, erguido décadas depois, é o atual

\footnotetext{
${ }^{2}$ Os fragmentos expostos sobre a entrevista também correspondem às memórias da aluna, que na ocasião acompanhou a fala do pesquisador Verneck Abrantes, concedida à Rádio Liberdade 96 FM.

${ }^{3}$ Pesquisadores pombalenses. Possuem variadas obras sobre a história de Pombal. A mais famosa dentre elas é "O Velho Arraial de Piranhas", de Wilson Seixas, membro do IHGP, publicada em 1962 com o intuito de realizar um apanhado histórico sobre o município, desde sua origem até sua elevação a categoria de cidade, passeando pelos fatos e atores históricos que marcaram o período. Pela sua grande contribuição aos estudos locais a obra tornou-se referência para os trabalhos posteriores, especialmente os de Verneck e Jerdivan, que participaram da revisão crítica do livro de Seixas e se dedicaram a estudar os vários aspectos que compõe a história da cidade - festas, arquitetura urbana, personagens políticos e religiosos.
} 
símbolo de uma civilização católica sertaneja num mundo árido, bárbaro, a ser conquistado.

ORIGEM, TRADIÇÃO E ARQUITETURA: A MONUMENTALIZAÇÃO DOS SABERES

Este breve texto apresenta uma análise introdutória dos saberes históricos elaborados para formação identitária de uma cidade que perdeu ao longo do século XIX sua centralidade política. Percebe-se que a partir da segunda metade do século XX instituíram-se verdades reproduzidas nos meios de ensino, nos espaços religiosos e na academia capazes de criar para si fatos de sua consagração civilizacional na região.

Notam-se simbologias comuns entre as fontes analisadas, todas apresentadas como fato incontestável de uma "qualidade histórica" para a cidade. São elas: a origem, a tradição religiosa (representada especialmente na Festa do Rosário), sua arquitetura (como a antiga cadeia, atual Casa da Cultura) e seus "filhos ilustres" (como o botânico Manuel Arruda Câmara, o cordelista Leandro Gomes de Barros e o economista Celso Furtado).

A Origem:

Grande Arruda, teus gestos teus feitos/Eloquentes fizeram medrar/O teu nome e por justos conceitos,/Fez o povo o teu ser consagrar./O Teodósio de Oliveira/Destemido brasileiro/ Desbravou esta ribeira/Com mui denodo, altaneiro;/Comissário, linda serra./Sobranceira, sem rival,/Simboliza e bem se encerra/Nas grandezas de Pombal!/O rincão grande Arruda acompanhas/Com um pálido de luz, sem igual;/Foi chamado Arraial de Piranhas/Que hoje em dia é chamado Pombal!/Padre Nobre, oh! Guerreiro valente!/Foste preso,/amarrado e escoltado/Pela estrada como um penitente,/Mas teu nome jamais olvidado./Argemiro, oh! Herói entre os bravos,/De Pombal um dos filhos queridos./Batalhaste em favor dos escravos,/Que viviam na Pátria oprimidos! [... $]^{4}$.

O hino da cidade de Pombal foi composto por Newton Pordeus Rodrigues Seixas, pai de Wilson Seixas (membro do IHGP). Os personagens que o hino elenca,

\footnotetext{
${ }^{4}$ Hino oficial da cidade Pombal, criado em 1956 (SEIXAS, 2004, p. 464-465).
} 
como o padre José Ferreira Nobre (Confederação do Equador), os Arrudas (família de militares, cientistas e intelectuais no período colonial e imperial) e os Oliveira Ledo (conquistadores coloniais dos sertões da Paraíba), serão os mesmos que o dentista/historiador, parente dos Carneiro Arnaud e Ruy Carneiro, levantará em sua famosa obra, "O velho arraial de Piranhas" (1964).

Esta obra, com o objetivo de traçar as origens do que viria se constituir a cidade Pombal, pensa como a conquista desse espaço, o primeiro núcleo habitacional do sertão paraibano, contribuiu para a conquista do sertão paraibano e para o surgimento de novos núcleos urbanos. Considerando o papel da família Oliveira Ledo como fundamental nesse processo, principalmente do sertanista Teodósio de Oliveira Ledo, Seixas dedicou algumas dezenas de páginas de sua obra para exaltar a família e demonstrar seus feitos.

O discurso utilizado por Seixas defende que a ação heroica de Teodósio e seus familiares é a marca principal das origens da cidade de Pombal; o seu espírito “destemido, denodo, altaneiro e desbravador" permitiu a esta família embrionária alcançar com "bom sucesso" a luta contra os tapuias, nativos que resistiam ao processo civilizador e, consequentemente, efetivar a instalação do Arraial das Piranhas - a base para a cidade de Pombal. Sob influência desta obra, muitos intelectuais, educadores e políticos passaram a forjar a concepção de uma cidade heroica, como bem expressa a professora Cessa Lacerda (2009) em seu poema: "Pombal, cidade heroica,/terra de lutas e vitórias,/de bravo [...]".

A tradição:

A cidade de Pombal está intimamente relacionada as festividades do mês de outubro, conhecida como Festa do Rosário. Iniciou-se em 1895, quando a Irmandade do Rosário recebeu o reconhecimento do bispo de Olinda e a autorização para receber doações destinadas aos reparos e manutenção da Igreja de Nossa Senhora do Rosário, a antiga Matriz do Bom Sucesso.

Segundo Verneck (2002, p. 43), “as primeiras comemorações se restringiam ao ato dos Mesários da Confraria percorrerem a feira arrecadando recursos financeiros, a singeleza da Procissão do Rosário [...] e à solenidade da Missa dentro da velha igreja". Mas com o passar dos anos, quando o profano se somou ao sagrado, a festa além de 
religiosa tornou-se ocasião propícia para a diversão em parques, jogos de azar, festas dançantes e consumo de bebidas alcóolicas. Uma expressão da fé católica, que começou timidamente, tomou espaço ao longo dos anos e tornou-se uma tradição.

As tradições são inventadas, sejam aquelas realmente criadas para um dado propósito, ou mesmo as que são mais difíceis de localizar, num dado tempo histórico, o momento do seu surgimento. Estas formas de expressão cultural inculcam sobre seus moradores valores e normas no presente embasados em signos de um passado histórico que foi ou são constantemente reapropriados. A festa do Rosário, assim, torna-se uma forma de reprodução idílica de um passado pombalense diante das transformações sociais do século XX, como meio de reforçar às novas gerações a importância de práticas do passado arraigadas às expressões identitárias no presente. (HOBSBAWM; RANGER, 1984)

Nesta ressignificação do passado para Pombal, as palavras do professor Francisco Vieira reforçam diante das apresentações dos negros dos Pontões, dos Congos ou do Reisado uma tradição para a festa do Rosário: um "misto de fé e calor humano"; é o momento mais esperado do ano, pois é a oportunidade de reencontrar e confraternizar com "os amigos vindos de lugares diversos e distâncias quilométricas"; é o momento de abraçar os que não via há anos (VIEIRA, 2010). É ainda o momento onde a fé e manifestações culturais se cruzam através das danças e cantos dos grupos folclóricos.

As expressões rurais e de uma cultura afrobrasileira se constituíram ainda no século XIX, e são mantidas por famílias que passam de geração a geração um símbolo regido pela tradição, algumas ainda ligadas a comunidades quilombolas. A festa tornouse um meio de ligação entre a cidade (o político), o sagrado (a religião católica) e a comunidade (moradores, camponeses e quilombolas). A homenagem ao Rosário, representação que circula em torno da sua igrejinha, testemunha a presença de personagens relegados a segundo plano numa história oficial da cidade e da região. As suas danças, momento crucial da festa, mostram um sincretismo secular não apenas com a religião católica, mas com mais um aspecto da sua identidade local.

A festa está intimamente ligada a formação da própria identidade pombalense, das memórias dos "filhos da cidade", como José Romero, que muito bem expressa isso através de um alerta: “[...] nunca esqueça a devoção ao Rosário, pois nada mais valioso 
para uma gente que a preservação de sua identidade e nossa identidade, com certeza, tem tangência com a festa dos negrinhos do Rosário" (CARDOSO, s.d.).

A arquitetura:

A antiga Igreja Matriz de Nossa Senhora do Bom Sucesso, hoje Igreja de Nossa Senhora do Rosário, guarda quase três séculos de história, tornando-se assim um símbolo do passado colonial pombalense; uma verdadeira relíquia que resistiu ao tempo. Sua arquitetura é um dos raros exemplos do barroco no sertão do Nordeste, e data de 1721 quando se inicia a construção de uma igreja em substituição a primeira capela de oração (construída em 1701 para administração dos sacramentos à pequena população local e aos índios) (FARIAS; KEHRLE; SOUSA; 2016).

Para os religiosos, a luta pelo empreendimento da obra é a prova máxima da fé de seus antepassados. Foi a fé em um Deus cristão e sua Virgem Mãe que "marcou a colonização do sertão" e impulsionou a construção da igreja (MARTINS, 2016, p. 9). Para esse público religioso, essa fé ainda é a mesma que move o pombalense em procissão no Domingo do Rosário, tradicional caminhada realizada no último dia da Festa do Rosário, quando os fiéis pagam suas promessas após terem alcançado alguma graça. É possível encontrar durante o trajeto algumas pessoas que seguem de joelhos, outras vestidas de branco ou com túnicas que remetem aos trajes franciscanos, algumas sem os calçados, com pedra na cabeça ou uma coroa de espinhos.

Em texto publicado em mídia social, o professor Francisco Vieira afirmou "Ser pombalense é antes de tudo nascer em Pombal, sob a égide da fé e a devoção a Nossa Senhora do Rosário" (VIEIRA, 2010). Mas ao lado da igreja há outra monumentalização arquitetônica do passado da cidade sertaneja: a Antiga Cadeia, hoje denominada "Casa da Cultura Senador Ruy Carneiro" (o museu municipal). A construção, iniciada em 1816 e concluída apenas no ano de 1858, foi considerada por muito tempo a maior e mais segura do sertão paraibano (SEIXAS, 2004, p. 422). O monumento, por onde "passaram criminosos que marcaram época", remete a antigos casos policiais que se tornaram emblemáticos, como Donária dos Anjos e o de Lucas, irmão do cangaceiro Jesuíno Brilhante. 
Por volta de 1877, durante uma das piores secas que o sertão enfrentou, a cidade de Pombal teria sido palco de um dos casos mais chocantes de sua população: um caso de antropofagia. Donária dos Anjos, 18 anos de idade, para sobreviver à fome assassinou uma criança e se alimentou de sua carne. A jovem teria cometido o ato em momento de aflição, por sentir-se "oprimida pela grande fome", segundo o depoimento prestado ao Juiz da comarca (SEIXAS, 2004, p. 416). Assim como outras cidades, Pombal não escapa da imagética de seca e da uma miserabilidade elaborada por uma série de discursos do início do século XX. (ALBUQUERQUE JR., 2009)

Como em "Cangaceiros e Fanáticos" (FACÓ, 2009), Pombal não está cercada apenas pela imagem da miséria de uma cidade esquecida pelo governo federal, mas também pela segurança pública. Lucas, irmão do cangaceiro Jesuíno Brilhante, foi preso na cidade de Pombal. Foi acusado por crime praticado em Catolé do Rocha, onde foi preso e transferido para a cadeira pública de Pombal, por volta do ano de 1874. A transferência de Lucas colocou a cidade na mira da pistola do cangaceiro Jesuíno, que às duas horas da madrugada do dia 19 de fevereiro atacou de surpresa a cadeia. $\mathrm{O}$ ataque que surpreendeu os soldados resultou em troca de tiros, rendição de policiais pelo grupo do cangaceiro, expropriação de armas e munições, e na fuga Lucas, que foi conduzido pelo irmão até a casa de seu pai.

A velha cadeia, hoje um museu, é a guarda de uma memória institucionalizada e reproduzida em estudos escolares, cuidadosamente organizada com o propósito de manter um rico acervo "ainda a ser descoberto e estudado". Sua arquitetura imperial destaca-se às demais residência de seu entorno. E apesar de não ser tombada pelo IPHAEP, seu significado mantem-se vivo por estudiosos desejosos em cristalizar uma memória para a cidade. Como não poderia deixar de ser, o edifício-museu mantém-se na literatura como um testemunho da grande seca e do ciclo do cangaço reforçados pelas estórias que o cercam, como as elaboradas para Donária e para Lúcio. (BEZERRA et al., 2014)

\section{Seus filhos ilustres:}

É com sentimento de orgulho que a festa do mês de julho, em comemoração ao aniversário da cidade, homenageia seus filhos ilustres, exaltando suas qualidades e 
relembrando suas origens. É recorrente a memória de homens como Celso Furtado, Leandro Gomes de Barro, Ruy e Janduy Carneiro, homens que alcançaram visibilidade no cenário estadual e nacional, por sua atuação social, cultural e política.

Em 2009, por exemplo, o economista Celso Furtado foi homenageado durante as comemorações dos 147 anos de elevação a categoria de cidade, cujo tema era "Nossa terra, nossa gente". As ruas da cidade se encheram de banners com seu nome e sua fotografia, as escolas começaram a explicar para seus alunos quem era Celso Furtado, onde ele havia nascido e qual sua importância para o país ${ }^{5}$. O mesmo acontece com relação a Leandro Gomes de Barro, alvo de homenagens em várias ocasiões: festa da cidade, 7 de setembro, data de nascimento e morte, etc.

Nomes como esses causam sentimento de orgulho a pombalenses, a ponto do professor Francisco Viera (2010) afirmar:

Ser pombalense é ostentar o orgulho de ser da terra de Rui e Janduy Carneiro - senador por quatro mandatos consecutivos - portanto, fato inédito na política nacional. E ainda de Celso Furtado, Leandro Gomes de Barros, Belarmino de França, Cessa Lacerda (poetisa), Arruda Câmara, Seu Chico, Wilson Seixas, Cel. Arruda e até o cangaceiro Chico Pereira. É inserido nestas lembranças destacar os Desembargadores Antônio Elias de Queiroga, Plínio Leite Fontes e Rafael Carneiro Arnaud - filhos de Pombal - terem honrosamente ocupado a Presidência do Tribunal de Justiça da Paraíba, cargo mais importante da magistratura estadual. $\mathrm{O}$ fato além de inédito é mais que uma honraria, um privilégio para uma cidadezinha do interior.

Apesar de sabermos que Celso Furtado mudou-se da sua cidade de origem com apenas 7 anos de idade e nunca mais voltar, sua memória enquanto pombalense é exaltada como a de quem nela viveu toda sua vida. O mesmo acontece com relação a Leandro Gomes de Barros e tantos outros que partiram do interior e não mais retornaram. Mas é este sentimento de orgulho insistentemente (re)elaborado por se pertencer a terra de Celso ou Leandro - homens reconhecidos pelo seu trabalho - que move discursos como o da poetisa pombalense, Cessa Lacerda:

\footnotetext{
${ }^{5}$ A coautora desse texto participou em praça pública das apresentações culturais, durante as festividades comemorativas, expondo um cordel que havia produzido em conjunto com outros alunos, cujo título era "Um cidadão de Valor: Celso Furtado". O cordel foi criado para contar um pouco da história do economista, exaltando sua origem e qualidades.
} 
Pombal de grandes artistas que figuram na história de músicos, poetas e repentistas que guardamos na memória. [...] Oh! Terra dos meus amores, de filhos ilustres e benfeitores de juristas e de guerreiros. Pombal de povo altaneiro que repercutiu vitória assim como Rui Carneiro que logrou honra e glória. Pombal, de Celso Furtado, que conquistou vida e glória, pois no mundo é reconhecido como o maior Economista da História. (FERNANDES, 2009)

\section{CONCLUSÃO: PONTOS PARA REFLEXÃO}

A práxis do ensino não perpassa por uma transmissão do conhecimento (professor-aluno), mas na capacidade da formação de sujeitos autônomos. Isto significa levar à sociedade homens e mulheres com capacidade crítica de leitura do mundo que os rodeia e, consequentemente, a que estão inseridos. A educação escolar parte da própria valorização do discente com o meio em que ele vive, seja na sala de aula, na residência com familiares ou amigos e na sua relação cotidiana que experimenta na cidade. (SOUSA, 2015)

A identidade social parte de múltiplos lugares e envolvem desde a relação de gêneros aos nacionalismos. São estas experiências, coletivas e individuais, que mesmo indiretamente perpassam pelo cotidiano da escola. A construção de identidades estereotipadas pelo conhecimento histórico (re)produzem-se em larga escala nas escolas e academias e tornam-se num espaço propício de cristalização de verdades que necessitam ser questionadas pelo próprio discente.

Buscamos apresentar imagens identitárias para uma cidade do interior da Paraíba, e como seus significantes são criados e explorados por sujeitos inseridos em lugares de poder. Seja em dias comemorativos ou em estudos acadêmicos, não é estranho encontrarmos signos que reforcem uma identidade com um passado idílico, reelaborados com propósitos normativos para usos no presente. Nossa intenção, neste primeiro passo de análise, foi provocar uma reflexão de como professores, intelectuais e acadêmicos continuam a reforçar estes lugares para uma formação determinista do presente, em que a importância da cidade reside em representações ilustres do passado. Estas imagens são pouco espelhadas pela realidade de seus moradores, os quais pouco se identificam com estes lugares do passado como reflexo do presente. Esta ordem necessita ser invertida, dando-se possibilidades de ação e criação aos educandos, aos 
seus transeuntes citadinos, para recriarem a própria história dos lugares vividos em sua cidade. Esta nova dinâmica rompe com velhos paradigmas que monumentalizam o passado.

Acreditamos que a valorização de um passado histórico deve partir do próprio sentido e da relação que os educandos têm com o espaço em que vivem. Monumentalizar o passado sem dar-lhe um sentido ao presente vivido, preservando-lhe como uma tradição a-histórica, é relegar aos estudantes a sua incapacidade crítica de entender a sua função social. A criação do presente a partir do passado deve partir da própria formação do estudante, percebendo-se como partícipe da história.

Os paradigmas dominantes sobre o mundo em que vivemos precisam ser questionados e reapresentados por novos conceitos, muitos deles elaborados num processo relacional, entre docente e discente, escola, cidade e sociedade.

\section{REFERÊNCIAS BIBLIOGRÁFICAS}

ABRANTES, Paulo. Em algum lugar chamado Pombal. 2010. Disponível em: http://clemildo-brunet.blogspot.com.br/2010/10/em-algum-lugar-chamado-pombal.html. Acesso em: 11 de agosto de 2017.

ALBUQUERQUE JR. Durval Muniz de. A invenção do Nordeste e outras artes. $4^{\mathrm{a}}$ Ed. Recife: FJN; Ed. Massangana; São Paulo: Cortez, 2009.

BEZERRA, Alian Maria Ferreira, et. al. Memorial fotográfico da cidade de Pombal-PB. Memorial apresentado como requisito para obtenção de crédito no Componente Curricular: Metodologia Científica do Mestrado em Docência da Educação, Faculdade do Norte do Paraná. 2014. Disponível em: http://www.redem.org/wpcontent/uploads/2014/06/memorial-escrito-1Cociencao1.pdf. Acessado em: 11 de agosto de 2017.

CARDOSO, José Romero. Festa do Rosário: tradição de um povo. s.d. Disponível em: http://rosariopombal.blogspot.com.br/. Acesso em: 11 de agosto de 2017. 
FACÓ, Rui. Cangaceiros e Fanáticos: gênese e lutas. Rio de Janeiro: Ed. UFRJ, 2009.

FERNANDES, Cessa Lacerda. Poema em homenagem a Pombal. In.: GOMES, Eliezer. Parabéns, Pombal querida! 147 anos de cidade. 2009. Disponível em: http://clemildobrunet.blogspot.com.br/2009/07/parabens-pombal-querida-147-anos-de.html. Acesso em: 11 de agosto de 2017.

HOBSBAWM; Eric; RANGER, Terence (orgs.). A invenção das tradições. Rio de Janeiro: Paz e Terra, 1984.

MARTINS, Maria do Socorro F. Portal de uma história. In.: FARIAS; KEHRLE; SOUSA. Inventário: Bens móveis e integrados da Igreja de Nossa Senhora do Rosário de Pombal/PB. João Pessoa: Mídia Gráfica, 2016.

SEIXAS, Wilson. O velho arraial de Piranhas (Pombal). $2^{\text {a }}$ ed. João Pessoa: Grafset, 2004

Sousa, Israel Soares de. Educação popular e ensino de História Local: cruzando conceitos e práticas. 238f. Tese (Doutorado) - Programa de Pós-Graduação em Educação, Centro de Educação, UFPB, João Pessoa, 2015.

SOUSA, Verneck Abrantes de. Um olhar sobre Pombal Antiga (1906 a 1970). João Pessoa: A União, 2002.

VIERA, FRANCISCO. Ser pombalense... 2010. Disponível em: http://clemildobrunet.blogspot.com.br/2010/10/ser-pombalense.html. Acesso em: 11 de agosto de 2017. 